\title{
RESEARCH
}

\section{Future strategy for United Kingdom research in accident and emergency medicine}

\author{
B A Foëx, F E Lecky, J P Wyatt
}

The article "Research in accident and emergency medicine" was offered up for debate. ${ }^{1}$ It asks important questions and raises some important issues. We would like to contribute some views on these and other issues, based on our experience in full time research.

\section{A historical perspective: lessons from around the world}

When searching for direction in an attempt to develop a strategy for research in United Kingdom accident and emergency ( $A \& E$ ) medicine, it makes good sense to look backwards and around the world. The list of countries where $\mathrm{A} \& \mathrm{E}$ medicine is organised in a similar way to the United Kingdom and where some academic development has occurred is rather short, but includes the USA, Canada, Australia, and New Zealand. Academic emergency medicine in both Australia and New Zealand is still very much at an embryonic stage.$^{23}$ It is only in North America (and most particularly the USA) where academic emergency medicine is established as a subspecialty. During its evolution over the past 10 years American would-be academic emergency physicians faced many similar problems to those facing us today.

Academic emergency medicine in the USA did not develop overnight. Instead it developed slowly from the efforts of a small number of individuals concentrated in a few centres in the midwest. These individuals initially struggled to become involved in large research projects and win prestigious grants. Collaboration with local specialists in larger specialties was used to gain expertise and involvement in large research projects. ${ }^{4}$ Now academic emergency physicians are winning grants totalling millions of dollars from the National Institute of Health (Weber J, personal communication, 1997).

\section{Collaboration}

Hardern et al suggest that collaboration between United Kingdom A\&E researchers would be needed to produce meaningful results. ${ }^{1}$ Such an idea is excellent in principle. In practice it may pose several problems: such collaboration may be logistically difficult to organise; and may suffer from varying degrees of enthusiasm of those involved. The "knock on" effect of the latter may be to adversely affect the quality of the data collected and make the conclusions less reliable. We entirely agree with their other point that collaboration with other specialties will be crucial. In the early stages of the academic development of our specialty, collaboration will help to build a sound scientific base. In the longer term a multidisciplinary approach will, as American emergency physicians have already discovered, provide additional skills and offer a different perspective to the problems faced in $A \& E$ medicine.

\section{The role of a central register}

The research committee of the Faculty of A\&E Medicine has established a database of published A\&E research. This could be extended to embrace the concept of a central register, which would allow easy collaboration between committed researchers. If the majority of large clinical trials and observational studies undertaken in A\&E departments were registered centrally, unintentional duplication could be avoided.

Given the resources, part of a registration process could be an independent evaluation of the proposed methodology for those studies which have not been peer reviewed before data collection. At this stage the questions of statistical power and previous work in the field could be addressed. The research committee of the faculty has started to encourage this process by informal analysis of proposed projects by $A \& E$ trainees during regional visits.

It would be unrealistic (and unreasonable) to burden the registration process with the responsibility for quality control. Peer review at the publication stage, although an imperfect tool, does at least aim to ensure that certain standards are met. Enthusiastic individuals should be encouraged, not prevented, from getting involved in research. A register should be used to provide direction, rather than to censor projects.

One further benefit of a central register would be to assist the future development of special interest groups. This will be an inevitable consequence of the expansion of $A \& E$ as a specialty. Special interest groups have been established in the USA, allowing researchers interested in the same field to meet to discuss relevant issues and future collaborative projects. ${ }^{5}$ The subjects covered by these groups range from the relatively specific (for example, 
asthma or CPR research) to the non-specific (for example, injury prevention).

\section{Concentration of resources}

Although the concept of spreading academic interest and expertise throughout a number of centres in the United Kingdom may sound attractive, it is unrealistic and has inherent disadvantages. A glance at the abstracts of recent faculty scientific meetings reveals the current concentration of $A \& E$ research within a handful of centres. This concentration of expertise enables trainees interested in research to receive informal training in an academic environment. It also offers some protection for consultants with significant research interests from the excessive administrative duties that limit American emergency physicians. ${ }^{67}$

Should there be a formal "concentration" exercise to provide the critical mass suggested for efficient and high quality research? Several criteria could be suggested along the lines of other research assessment exercises. These might include:

(1) Proven track record:

External funding: MRC, Wellcome, Royal Colleges

Higher degrees achieved within the centre

Publications resulting from projects

(2) Collaboration across or within the specialty:

International

National

Local.

At the moment there are probably only a handful of centres which clearly fit these criteria. However, this will be a dynamic process and is likely to change once people start to be trained and move away from the established centres, but it may take many years.

\section{Aim of the research effort}

It is an oversimplification to focus directly and purely on randomised controlled clinical trials (RCTs) aimed at "the improvement of patient outcomes." Some important issues, such as accident prevention, and a determination of the best system for delivering emergency care, deserve attention but are not easily investigated using RCTs. Also-and most importantly-if the specialty is to have a scientific base to work from, there must also be an element of basic science research (for example, elucidating various pathophysiological mechanisms) where patient outcomes are a distant target. For example, the hypothesis driving the racent RCT in Houston (which is probably the best current evidence relating to fluid resuscitation) was generated by painstaking laboratory investigation as well as by a review of historical reports. ${ }^{89}$ High quality basic science contributed by $A \& E$ specialists will reveal new directions for clinical research.

The precise allocation of resources should be determined by the quality of the research proposals rather than according to any fixed quota between basic and clinical projects. It may be that at different times the proportions will vary.
Initially, as collaboration with basic science departments is likely to be very important, there may be a preponderance of basic science research. In years to come there is likely to be more clinical research, led by those who were trained in the early years.

\section{The need to encourage research and identify priorities}

Regardless of A\&E practitioner involvement, research which affects the management of A\&E patients will continue to occur. It must be an advantage for patients and the specialty if this research benefits from the skills and perspectives of those who work in A\&E. Prioritisation may be important but should be informed by recognition of areas in which $A \& E$ researchers have a track record for producing important work. The current Cochrane review of RCTs in emergency medicine should identify areas where practice is not supported by high quality evidence. This organisation rigorously hand searches journals and conference proceedings for RCTs. Where feasible and appropriate, Cochrane interest groups will synthesise trial data to provide systematic reviews. These reviews are updated and acknowledged as "best evidence" on the effectiveness of treatment.

\section{Training in research}

It is imperative that the issue of training in research is addressed. This will prove to be essential in order to provide the specialty with a high quality research base from which it can improve patient care and, in a sense, control its own destiny.

Adequate formal research training was not a part of the old system of higher specialist training, which allocated a half day a week for registrars and a whole day for senior registrars. Similarly, it is unlikely to be achieved within the new Calman training programme. ${ }^{1011}$ In order to establish scientific credibility, proper scientific training of those interested in research is essential. A full time commitment is required to prevent the researcher from being distracted by $A \& E$ clinical and administrative work. The best way that this can be achieved is through full time work for a higher degree in an environment providing adequate guidance and supervision. At present, this cannot be provided exclusively within the specialty. As in the USA, it is clear that would-be United Kingdom academic A\&E physicians will need to collaborate in training with other groups. This collaboration has many advantages, as described above.

The aim of training in research is to acquire scientific skills and an understanding of the research process, in addition to completing a well designed project. This requires major funding, as in most instances the research training period will last much longer than the year allowed for within the specialist registrar Calman programme. The limited funding at the disposal of the Faculty of A\&E Medicine will be largely irrelevant to this training. The real funding will have to come from the MRC, the Wellcome Trust, Universities, and other 
bodies offering training fellowships. Competition for these is intense. Trainees in A\&E are in a difficult position, since working in a unit with a reputation for high quality research is a prerequisite for consideration for some of these awards. The answer, once again, lies in collaboration with other academic groups. Training fellowships offered by the Royal College of Surgeons of England may provide a useful model for the use of resources, which the Faculty of A\&E Medicine has yet to acquire.

So, should all trainees receive some training in research? Clearly the full time training we have described is impossible for large numbers: there is not the funding and there are not enough people to supervise the training. Recent discussions with trainees suggest that the vast majority have very little interest in research anyway. The situation seems no different in other specialties: a number of trainees do get farmed out to basic science laboratories for variable periods of time to do projects about which they express varying degrees of enthusiasm. Many admit that the work will never be properly written up unless their careers depend on it.

The recently introduced specialist registrar training programme offers little incentive to take the necessary time out for research training. ${ }^{11}$ Almost invariably there is a heavy financial penalty for doing so. This is coupled with potential difficulties trying to retain training status, such that there may be no guarantee of re-entry into the training programme. The new training programme does allow a year of research. As we have found out, although a week may be a long time in politics, a year is a very short time in research. A year may be adequate for a systematic literature review, but will be insufficient for any prospective clinical study or any laboratory work unless the researcher has ample opportunity to prepare the whole thing in advance or can slot into a rolling programme of work.

The number of junior $A \& E$ doctors now undergoing research training is such that it will be some time before there are enough trained academics within the specialty to train the next generation without collaboration with other specialties. This should not deter the Faculty of $A \& E$ Medicine, which should encourage high quality basic scientific or clinical epidemiological work. This work will inevitably occur in centres where expertise is concentrated and where there is active collaboration with other specialties.

\section{Final thoughts}

The idea that a central body can dictate rather than facilitate the nature of the $A \& E$ research effort may be a sign that the specialty is trying to run before it can walk. ${ }^{1}$ There is a world of difference between the skills needed to carry out original research and the ability to appraise published research. There is also a difference between directing trainees into low impact, self limiting studies (even in "priority" areas) and recognising what is needed to establish the scientific credibility of our young specialty: motivated individuals in centres capable of providing a proper training in research.

1 Hardern RD, Hamer DW, Gray A, McGowan A, Clancy MJ. Research in accident and emergency medicine. J Accid Emerg Med 1997;14:118-9.

2 Cameron PA, Bradt DA, Ashby A. Emergency medicine in Australia. Emerg Med 1996;28:35-9.

3 Kelly A. Towards academic emergency medicine in Australasia. Emerg Med 1996;28:35-9.

4 Simons-Morton DG. Funding avenues for research in emergency medicine at the National Institute of Health and the National Heart, Lung and Blood Institute. Acad and the National Heart, Lung

5 Sanders AB. The maturation of academic emergency medicine. Acad Emerg Med 1995;2:336-7.

6 Sanders AB, Spaite DW, Smith R, Criss E. Allocation of time in three academic specialities. J Emerg Med 1988;6:435-7.

7 Rosen P, Harwood-Nuss A. The academics of emergency medicine. J Emerg Med 1988;6:425-6.

8 Bickell WH, Wall MJ, Pepe P, Martin RR, Ginger, VF, Allen $\mathrm{MK}$, et al. Immediate versus delayed fluid resuscitation fo hypotensive patients with penetrating torso injuries. N Eng J Med 1994;331:1105-9.

9 Bickell WH, Bruttig SP, Millnamow GA, O'Benar J, Wade $C E$. The detrimental effects of intravenous crystalloid after aortotomy in swine. Surgery 1991;36:529-36.

10 Joint Committee on Higher Specialist Medical Training. Training in accident and emergency medicine. London: JCHM, 1991.

11 Department of Health. Hospital doctors: training for the future. The report of the working group on specialist medical training. London: Department of Health, 1993. 